\title{
The predictive value of sequential cervical length screening in singleton pregnancies after cerclage: a retrospective cohort study
}

\author{
Sophie Pils ${ }^{1}$, Wolfgang Eppel ${ }^{1}$, Regina Promberger ${ }^{2}$, Max-Paul Winter $^{3}$, Rudolf Seemann ${ }^{4}$ and Johannes Ott ${ }^{{ }^{*}}$
}

\begin{abstract}
Background: There are few valid predictors for preterm delivery after cerclage. Experience with a screening program that included four sequential cervical length measurements in singleton pregnancies after cerclage is reviewed.

Methods: In this retrospective cohort study, 88 singleton pregnancies after cerclage were included. Cervical length $(\mathrm{CL})$ measurements were performed perioperatively and at weeks $16+0,18+0,20+0$, and $22+0$ by transvaginal ultrasound. Predictive factors for early preterm delivery included patient characteristics, obstetric history and $\mathrm{CL}$ measurements and were analyzed separately for women with ultrasound-indicated cerclage and those with historyindicated cerclage. Women with emergency cerclage were excluded.
\end{abstract}

Results: In women with delivery $<35$ weeks, $C L$ declined from the $16+0$ to the $22+0$ weeks of gestation $(p=0.009)$. In univariate analysis, all CL measurements were predictive for delivery $<35$ weeks in women who underwent ultrasound-indicated cerclage and in women who received a history-indicated cerclage, whereas in multivariate analysis only $\mathrm{CL}$ three to six days after cerclage remained significant (odds ratio $0.85,95 \% \mathrm{Cl} 0.73-0.98$ ). In women with ultrasound-indicated cerclage, optimized cut-off was $\leq 20 \mathrm{~mm}$ (specificity $83.8 \%$, sensitivity $84.2 \%$ ).

Conclusions: $\mathrm{CL}$ measured three to six days after cerclage placement provides the best information about the risk for delivery $<35$ weeks.

Keywords: Cerclage, Cervical length, Preterm delivery, Delivery, Cervical insufficiency

\section{Background}

Preterm birth is a major determinant of fetal outcome and main cause of neonatal morbidity and mortality [1]. Cervical insufficiency is a well-documented etiological factor in preterm delivery (PTD) with an inverse relation between cervical length (CL) and gestational age at delivery $[2,3]$. Management strategies for the prevention of PTD include progesterone treatment, vaginal pessaries, and surgical approaches [2, 4]. Although pre- and postconceptional abdominal cerclage has been suggested and evaluated in various studies [5] the main surgical approach is to reinforce the cervix by encircling the bottom half of the endocervical canal and thus compressing

\footnotetext{
* Correspondence: johannes.ott@meduniwien.ac.at

${ }^{1}$ Department of Obstetrics and Gynecology, Medical University of Vienna,

Waehringer Guertel 18-20, 1090 Vienna, Austria

Full list of author information is available at the end of the article
}

it (cerclage) [6]. Depending on indication as well as on characteristics of the pregnancy, women may benefit from cerclage to delay early delivery [1, 7]. From a mechanistically determined point of view, cerclage is assumed to provide structural support to prevent the dynamics of cervical lenght change during rising intrauterine/transfundal pressures [8]. In addition, this procedure might help to maintain at least a mechanical barrier that protects against ascending pathogens [1].

Despite the positive effects on the duration of the pregnancy, there is a lack of valid predictors for PTD after cerclage placement [9]. Fetal fibronectin is also considered a helpful tool to predict upcoming delivery, but the mechanical complications of the cerclage, like displacement, require direct visualization of the cervix and the test is invalid after cervical surgery $[9,10]$, which makes serial ultrasound examinations the method 
of choice [11]. However, there is just two reports on serial CL measurements after cerclage [12, 13]. We, thus, aimed to focus on this issue. By studying women after cerclage, we intended to critically review our experience with sequential CL screening which has been implemented at our department. Thus, the main study objective was to evaluate the kinetics of CL in pregnancies after cerclage. To predict early preterm delivery (early PTD) before the 35th gestational week, we also aimed to test the value i) of perioperative $\mathrm{CL}$ measurements and basic patient characteristics that would allow an early prediction shortly after the operation, and ii) of sequential measurements.

\section{Methods}

As reported previously [14], a screening program for pregnant women at perceived risk for PTD has been established for many years at the Department of Fetomaternal Medicine of the Medical University of Vienna, Austria. At the department, the annual number of deliveries was at least 2500 during the study period. The department is the national reference center for fetomaternal medicine in eastern Austria. Women with a history of previous PTD due to cervical insufficiency, preterm labor, preterm premature rupture of membranes, a previous 2nd trimester miscarriage or a previous conization were included, as well as women who had undergone cerclage in a current pregnancy. The screening program included CL measurement by transvaginal ultrasound in the $16+0,18+0,20+0$, and $22+$ 0 weeks of gestation. All ultrasound examinations were performed by highly experienced operators (either obstetricians or certified medical-technical assistants). All CL measurements were carried out according to the guidelines of the Fetal Medicine Foundation (available online at http://www.fetalmedicine.com/fmf/ training-certification/certificates-of-competence/cervical-assessment/). The shortest of at least three measurements was documented.

From June 2000 to December 2012, a total of 222 cerclage procedures were performed. In this retrospective analysis, we included women with (i) a singleton pregnancy, (ii) a history of previous PTD (i.e. $22+0-36$ +6 ) or 2nd trimester miscarriage who (iii) underwent cerclage in the current pregnancy. The study population had regular follow-up examinations, beginning with first-trimester screening, and must have given birth at the department from January 2001-July $2013(n=88)$. Notably, according to the local guidelines, which is based on previous reports $[15,16]$ for women at risk for PTD, women were offered an ultrasound-indicated cerclage if the CL was $<25 \mathrm{~mm}$ which was the case for $56 / 88$ women (63.6 \%). However, 32 women (36.4\%) underwent the procedure on their own demand regardless of
CL. They insisted on being treated with a historyindicated cerclage due to their poor obstetric history. At the $16+0,18+0$ and $20+0$ week, 52 (59.1\%), 76 $(86.4 \%)$ and $88(100.0 \%)$ had undergone cerclage, respectively.

We excluded women with multiple pregnancies $(n=$ $32)$, women with emergency cerclage $(n=30)$, those who had to be delivered electively preterm for maternal-fetal complications $(n=39)$ and those who delivered at another department and, thus, were lost to follow-up ( $n=$ 33). This resulted in a patient population of 88 women after cerclage. None of the women had been treated with prophylactic progesterone.

The main outcome measure was early PTD before 35 week of gestation in accordance with recent studies $[11,14]$. This also included cases of second trimester miscarriage due to cervical insufficiency (defined as painless cervical dilatation leading to second-trimester birth), preterm labor, or preterm premature rupture of membranes. This study was approved by the Institutional Review Board of the Medical University of Vienna (IRB number: 1730/2013).

Retrospective acquisition of all relevant data was performed using the Viewpoint ${ }^{\circ}$ software (GE Healthcare, Wessling, Germany) which is the basic perinatologic database at the department. CL measurements were done one day before and after a median of 4 days (IQR 3-6) after cerclage as well as at weeks $16+0,18+0,20$ +0 and $22+0$. In addition, the following parameters were included: history of previous conization procedures, age at delivery, body mass index (BMI) at the initial visit, parity, previous preterm birth due to cervical insufficiency, preterm labor, or preterm premature rupture of membranes, previous 2nd trimester miscarriage, pregnancies after in-vitro-fertilization (IVF), urinary tract infection during pregnancy, and cigarette smoking.

All women in the cohort were treated with the modified Shirodkar technique. Accordingly, a $5 \mathrm{~mm}$ Mersilene ${ }^{\circ}$ Polyester Fiber Suture (Ethicon Inc., Somerville, New Jersey, USA) was passed anteriorly to posteriorly on the cervix. The tape was tied anteriorly, and the cervical mucosa was then closed with continuous stitches [17].

Neither written nor verbal informed consent is necessary in retrospective studies according to the Ethics Committee of the Medical University of Vienna and was, thus, not obtained.

\section{Statistical analysis}

Nominal variables are reported as numbers and frequencies, and continuous variables as medians and interquartile ranges (IQR). Paired t-tests were applied to test for differences between subsequent $\mathrm{CL}$ measurements within one group. An unpaired $t$-test was used to test 
for the differences in initial CL between women with and without early PTD For t-tests, data had to be normally distributed as evaluated by KolmogorowSmirnow-Test. This was the case for all of these analyses. For $\mathrm{t}$-tests, the $\mathrm{t}$-value and the degree of freedom $(\mathrm{dg})$ are provided. In a stepwise linear regression model for prediction of early PTD, we included the following parameters in addition to baseline patient characteristics: i) basic patient characteristics, ii) the CL before and after cerclage, the dynamics between these measurements, and iii) the CL at the completed 20 and 22 weeks of gestation. These analyses were performed to allow an early prediction of early PTD shortly after cerclage. Women with history-indicated and ultrasound-indicated cerclage were analysed separately. The optimal cut-off for CL was calculated as the threshold value with the highest specificity and sensitivity based on the receiver-operating characteristics (ROC) curve as a sensitivity versus (1specificity) plot. The discriminatory ability of the investigated parameters is described as the correlation between specificity and sensitivity, and was measured by the area under the receiver-operating (AUC) curve. Where appropriate, values are given with a $95 \%$ confidence interval $(95 \% \mathrm{CI})$. Statistical analysis was performed using the open-source statistical package, $\mathrm{R}$ (version 2.13.0; available online at http://www.r-project.org/). Differences were considered statistically significant if $p<0.05$.

\section{Results}

Of the cases, $20(22.7 \%)$ delivered at $<35$ weeks of gestation. In addition, four women $(4.5 \%)$ suffered from a second trimester miscarriage (22-24 weeks). This resulted in an overall rate for early PTD $<35$ weeks used for the following analyses of $27.3 \%$ (24/88). Details on patient characteristics are shown in Table 1. This Table also provides a comparison to the 33 women lost to follow-up.

Details about changes in CL are provided in Fig. 1. CL at 16 weeks gestation did not differ between women with and without previous early PTD $(n=64$; median $30 \mathrm{~mm}$, IQR $23-38$ vs. $n=24$; median $24 \mathrm{~mm}$, IQR $17-$ 34; $p=0.953$ with $t=1.357$ and $\mathrm{df}=87$ in unpaired $t$-test, respectively). When comparing week $16+0$ to weeks 18 +0 and $20+0$, significant shortening in $\mathrm{CL}$ was found in women with early PTD ( $p=0.026$ with $t=2.423$ and df $=47$ and $p=0.009$ with $t=2.930$ and $\mathrm{df}=47$ in paired $t$ test, respectively), whereas in women without early preterm delivery, there were no significant differences $(p=$ 0.816 with $t=-0.234$ and $\mathrm{df}=127$ and $p=0.088$ with $t=$ 1.736 and $\mathrm{df}=127$ in paired $t$-test, respectively).

For both women who had undergone ultrasoundindicated cerclage (early PTD: 19/56, $33.9 \%$; Table 2) and women who had undergone history-indicated cerclage (early PTD: 5/32, $15.6 \%$; Table 3), the logistic
Table 1 Basic patient characteristics: comparison of the analysed study population and patients lost to follow-up

\begin{tabular}{|c|c|c|c|}
\hline & $\begin{array}{l}\text { Analzyed patients } \\
(n=88)\end{array}$ & $\begin{array}{l}\text { Lost to follow-up } \\
(n=33)\end{array}$ & $p$ \\
\hline$\overline{\text { Age }(\text { years) }}{ }^{c}$ & $31(29 ; 36)$ & $32(27 ; 38)$ & 0.828 \\
\hline Body mass index $\left(\mathrm{kg} / \mathrm{m}^{2}\right)^{c}$ & $24.1(20.9 ; 28.5)$ & $22.2(21.1 ; 26.4)$ & 0.604 \\
\hline Previous preterm delivery ${ }^{d}$ & $40(45.5)$ & $15(45.5)$ & 1.000 \\
\hline $\begin{array}{l}\text { Previous second trimester } \\
\text { miscarriage }^{d}\end{array}$ & $59(67.0)$ & $20(60.6)$ & 0.508 \\
\hline Previous conization $^{d}$ & $15(17.0)$ & $4(12.1)$ & 0.587 \\
\hline $\begin{array}{l}\text { Pregnancy after IVF } \\
\text { treatment }^{d}\end{array}$ & $5(5.7)$ & $4(12.1)$ & 0.254 \\
\hline $\begin{array}{l}\text { Urinary tract infection } \\
\text { during pregnancy }\end{array}$ & $2(2.3)$ & $3(9.1)$ & 0.124 \\
\hline \multirow[b]{4}{*}{ Cigarette smoking $^{d}$} & 19 (21.6) & $8(24.2)$ & 0.932 \\
\hline & $31(35.2)$ & $11(33.3)$ & \\
\hline & $38(43.2)$ & $14(42.4)$ & \\
\hline & $15(17.0)$ & $3(9.1)$ & 0.392 \\
\hline $\begin{array}{l}\text { Gestational age } \\
\text { at cerclage }\end{array}$ & $16(16 ; 18)$ & $16(16 ; 18)$ & 0.496 \\
\hline
\end{tabular}

regression models' univariate analyses revealed that all perioperative $\mathrm{CL}$ parameters differed significantly between women with and without early PTD. In multivariate analyses, all parameters that had been significant in the univariate models were included apart from the parameter "decrease in CL after cerclage", due to its colinear association ( $\mathrm{t}$-value 9.267, $p<0.001$ ) with the parameters "CL before cerclage" and "CL after cerclage," which were also more predictive univariately. Notably, only $\mathrm{CL}$ after cerclage remained significant (ultrasound-




Table 2 Prediction of early preterm delivery in women who had undergone cerclage for cervical shortening. Results of the univariate and multivariate analysis

\begin{tabular}{|c|c|c|c|c|c|c|c|c|}
\hline & \multirow[b]{2}{*}{$\begin{array}{l}\text { Delivery <35 week } \\
(n=19)\end{array}$} & \multirow[b]{2}{*}{$\begin{array}{l}\text { Delivery } \geq 35 \text { week } \\
(n=37)\end{array}$} & \multicolumn{3}{|l|}{ Univariate analysis } & \multicolumn{3}{|c|}{ Multivariate analysis } \\
\hline & & & OR $(95 \% C l)^{a}$ & $\begin{array}{l}\mathrm{P} \\
\text { (Wald's test) }\end{array}$ & $\begin{array}{l}\mathrm{P} \\
(\text { LR test })^{\mathrm{b}}\end{array}$ & $\begin{array}{l}\text { Adjusted OR } \\
(95 \% \mathrm{Cl})^{\mathrm{a}}\end{array}$ & $\begin{array}{l}\text { P } \\
\text { (Wald's test) }\end{array}$ & $\begin{array}{l}\mathrm{P} \\
(\mathrm{LR} \text { test })^{\mathrm{b}}\end{array}$ \\
\hline Age $(\text { years })^{c}$ & $33(27 ; 38)$ & $31(29 ; 36)$ & $1.01(0.92,1.12)$ & 0.758 & 0.757 & - & - & - \\
\hline Body mass index $\left(\mathrm{kg} / \mathrm{m}^{2}\right)^{c}$ & $24.8(21.0 ; 30.4)$ & $23.2(20.2 ; 27.2)$ & $1.09(0.96,1.23)$ & 0.189 & 0.183 & - & - & - \\
\hline $\begin{array}{l}\text { Previous preterm } \\
\text { delivery }^{\text {d }}\end{array}$ & $7(36.8)$ & $22(59.5)$ & $0.4(0.13,1.24)$ & 0.113 & 0.107 & - & - & - \\
\hline $\begin{array}{l}\text { Previous second trimester } \\
\text { miscarriage }^{\mathrm{d}}\end{array}$ & $13(68.4)$ & $20(54.1)$ & $1.84(0.58,5.9)$ & 0.304 & 0.297 & - & - & - \\
\hline Previous conization ${ }^{d}$ & $3(15.8)$ & $9(24.3)$ & $0.33(0.09,1.21)$ & 0.094 & 0.072 & - & - & - \\
\hline $\begin{array}{l}\text { Pregnancy after IVF } \\
\text { treatment }^{d}\end{array}$ & $3(15.8)$ & $2(5.4)$ & $3.28(0.5,21.6)$ & 0.217 & 0.211 & - & - & - \\
\hline $\begin{array}{l}\text { Urinary tract infection } \\
\text { during pregnancy }\end{array}$ & $0(0)$ & $1(2.7)$ & $0(0, \ln f)$ & 0.992 & 0.360 & - & - & - \\
\hline \multirow{3}{*}{ 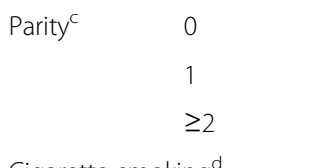 } & $8(42.1)$ & $4(10.8)$ & reference & reference & 0.292 & - & - & - \\
\hline & $6(31.6)$ & $15(40.5)$ & $0.33(0.02 ; 5.03)$ & 0.427 & & - & - & - \\
\hline & $5(26.3)$ & $18(48.6)$ & 0 (0;inf) & 0.996 & & - & - & - \\
\hline Cigarette smoking $^{d}$ & $3(15.8)$ & $7(18.9)$ & $0.8(0.18,3.54)$ & 0.772 & 0.770 & - & - & - \\
\hline $\begin{array}{l}\text { Gestational age at } \\
\text { cerclage }^{c}\end{array}$ & $16(16 ; 18)$ & $16(16 ; 18)$ & $1.14(0.66,1.96)$ & 0.634 & 0.633 & - & - & - \\
\hline $\begin{array}{l}\mathrm{CL}^{\mathrm{e}} \text { before cerclage } \\
(\mathrm{mm})^{c}\end{array}$ & $17(14 ; 20)$ & $23(17 ; 24)$ & $0.89(0.8,0.99)$ & $0.036^{f}$ & $0.028^{f}$ & $0.98(0.86,1.13)$ & 0.808 & 0.809 \\
\hline $\mathrm{CL}^{\mathrm{e}}$ after cerclage $(\mathrm{mm})^{\mathrm{c}}$ & $14(9 ; 19)$ & $27(22 ; 32)$ & $0.82(0.74,0.91)$ & $<0.001^{f}$ & $<0.001^{f}$ & $0.85(0.73,0.99)$ & 0.041 & $0.024^{f}$ \\
\hline $\begin{array}{l}\text { Decrease in } \mathrm{CL}^{\mathrm{e}} \text { after } \\
\text { cerclage }^{\mathrm{d}}\end{array}$ & $13(68.4)$ & $7(18.9)$ & $9.29(2.61,33.06)$ & $<0.001^{f}$ & $<0.001^{f}$ & \multicolumn{3}{|c|}{ Not included due to redundancy } \\
\hline $\begin{array}{l}\mathrm{CL}^{\mathrm{e}} \text { at the } 20 \text { gestational } \\
\text { week }(\mathrm{mm})^{\mathrm{c}}\end{array}$ & $16(10 ; 23)$ & $24(21 ; 31)$ & $0.84(0.76,0.93)$ & 0.001 & $<0.001^{f}$ & $0.98(0.82,1.16)$ & 0.803 & 0.803 \\
\hline $\begin{array}{l}\mathrm{CL}^{\mathrm{e}} \text { at the } 22 \text { gestational } \\
\text { week }(\mathrm{mm})^{\mathrm{c}}\end{array}$ & $15(5 ; 23)$ & $20(16 ; 29)$ & $0.89(0.83 ; 0.97)$ & 0.007 & $0.002^{f}$ & $0.97(0.87,1.08)$ & 0.595 & 0.593 \\
\hline
\end{tabular}

${ }^{\mathrm{a}}$ OR $(95 \% \mathrm{Cl})=$ odds ratio $\left(95 \%\right.$ confidence interval), ${ }^{\mathrm{b}} \mathrm{LR}$ test $=$ likelihood ratio test, ${ }^{\mathrm{c}}$ Continuous variable, provided in median (interquartile range); ${ }^{\mathrm{d}}$ nominal variable, provided in $\mathrm{n}(\%) ;{ }^{\text {e }} \mathrm{CL}=$ cervical length; ${ }^{\mathrm{f}}$ Italic letters indicate statistical significance; ${ }^{9}$ despite its significant predictive value in the univariate analysis, the parameter "cervical length before cerclage" was not included in the multivariate model due to its co-linear association with the parameter "cervical length after cerclage" that was more predictive in the univariate analysis

indicated: OR 0.85, $95 \%$ CI: 0.73-0.98; $p=0.022$; history-indicated: OR $0.85,95 \% \mathrm{CI}: 0.75-0.96 ; p=$ 0.004).

In women after ultrasound-indicated cerclage, the optimized cut-off for the prediction of early preterm delivery was a CL three to six days after cerclage $\leq 20 \mathrm{~mm}$ (area under the curve: 0.867 ) which resulted in specificity, sensitivity, and positive and negative predictive values of 83.8 \% (95 \% CI: 61.9-93.7), $84.2 \%$ (95 \% CI: 60.4-96.6), $72.7 \%$ (95 \% CI: 49.8-89.3), and $91.2 \%$ (95\% CI: 76.3-98.1), respectively. Of the 22 women with a CL $\leq 20 \mathrm{~mm}, 16(72.7 \%)$ had early PTD compared to $3 / 34(8.8 \%)$ women with a CL $>20 \mathrm{~mm}(p<0.001)$.

In women after history-indicated cerclage, the optimized cut-off was $\leq 33 \mathrm{~mm}$ (area under the curve: 0.915 ) which resulted in specificity, sensitivity, and positive and negative predictive values of $83.3 \%$ (95 \% CI: 61.9-93.7), 100.0 \% (95 \% CI: 40.3-100.0), 55.5 \% (95 \% CI: $18.7-$
81.3), and $100.0 \%$ (95 \% CI: 80.7-100.0), respectively. Four/10 (40 \%) women with a CL $\leq 33 \mathrm{~mm}$ had early PTD compared to $1 / 12(8.3 \%)$ women with CL >33 mm $(p=0.135)$.

\section{Discussion}

This retrospective study on singleton pregnancies after cerclage provided the following key findings: i) in cases that resulted in an early PTD, CL shortened significantly from week 16 to measurements obtained at time points thereafter; ii) the absolute CL three to six days after cerclage was the most predictive parameter for early PTD regardless from the indication for cerclage; and iii) for this specific measurement, a threshold of $\leq 20 \mathrm{~mm}$ gives the most accurate information about the risk for early PTD after cerclage in women who had undergone ultrasound-indicated cerclage. 
Table 3 Prediction of early preterm delivery in women who had undergone cerclage regardless of cervical length. Results of the univariate and multivariate analysis

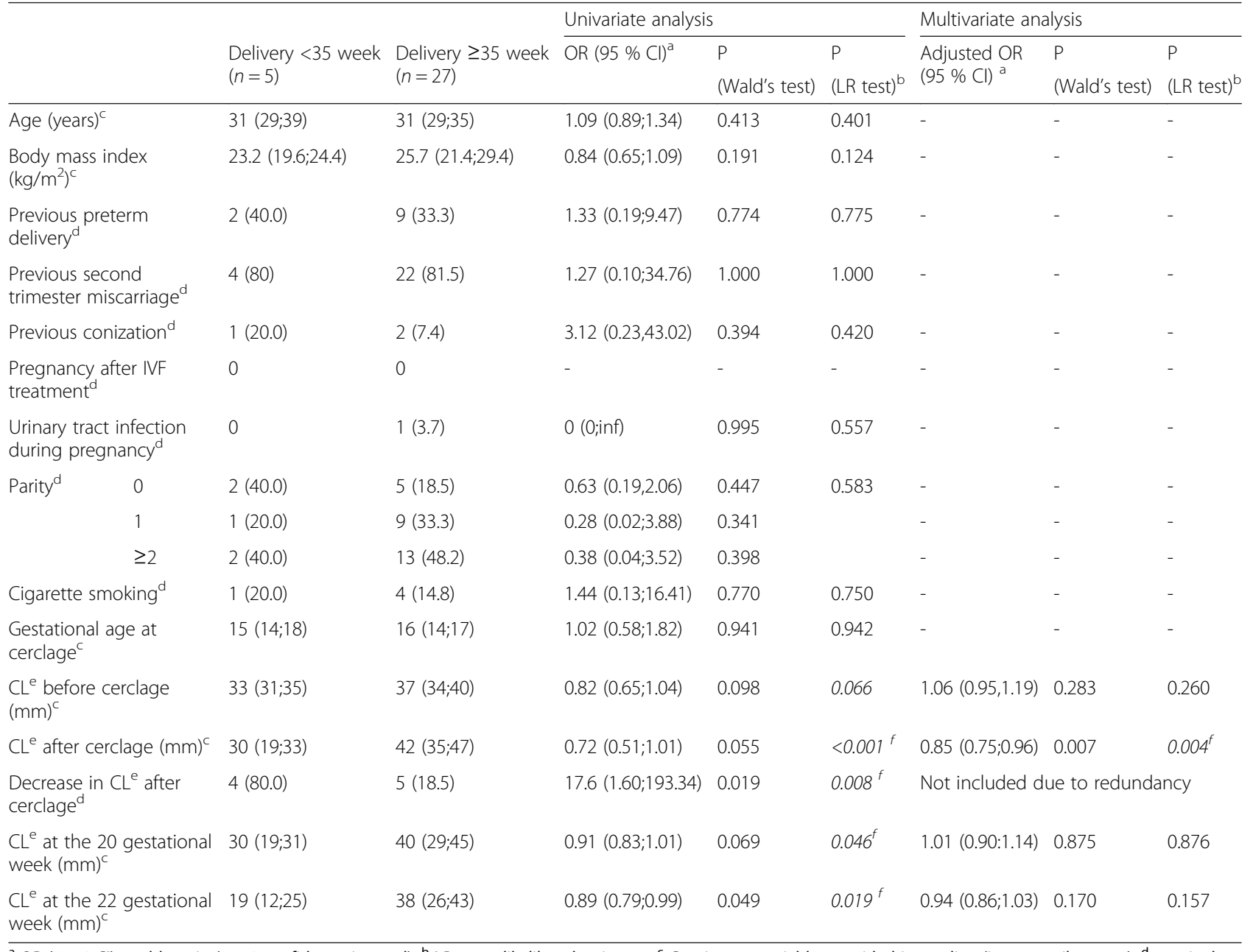

${ }^{a}$ OR $(95 \% \mathrm{Cl})=$ odds ratio $\left(95 \%\right.$ confidence interval), ${ }^{\mathrm{b}}$ LR test $=$ likelihood ratio test, ${ }^{\mathrm{c}}$ Continuous variable, provided in median (interquartile range); ${ }^{\mathrm{d}}$ nominal variable, provided in $\mathrm{n}(\%) ;{ }^{\mathrm{e}} \mathrm{CL}=$ cervical length; ${ }^{\mathrm{f}}$ Italic letters indicate statistical significance; ${ }^{9}$ despite its significant predictive value in the univariate analysis, the parameter "cervical length before cerclage" was not included in the multivariate model due to its co-linear association with the parameter "cervical length after cerclage" that was more predictive in the univariate analysis

Besides the small sample size, we consider the retrospective design of our study as a limitation, since it might have introduced bias. For example, a selection bias is possible, since we cannot prove that all women at perceived risk have undergone the screening program. Unfortunately, 33 women were lost to follow-up. We consider this circumstance of minor relevance, since, as demonstrated in Table 1, patient characteristics did not differ between analyzed women and those lost to followup. Moreover, the lack of various other parameters that have been suggested as predictive of the duration of pregnancy after cerclage needs to be emphasized. A previous report claimed that shortening $C L$ at week 26 was highly predictive for early PTD [10]. Since we aimed to evaluate early predictive parameters, we did not focus on $\mathrm{CL}$ at this gestational age. Furthermore, we cannot comment on cervical funneling [12, 18, 19]. This information could not be reliably evaluated by retrospective chart review. Neither can we provide details on cerclage height [20].

It has to be mentioned that one could be concerned about the terms "ultrasound-indicated" and "history-indicated" cerclage which was based on a Cochrane database review [16]. However, the latter could also be named "elective" as used in a recent report [13]. We hope that the exact definitions provided in the Methods Section will make replicability and comparability to other studies possible.

The mechanism of action of cerclage is poorly understood, a mechanical component has been suggested [8]. This assumption is supported by CL shortening in women with early PTD (Fig. 1). Similar prospective data have already been reported [21] and the authors concluded that serial CL measurements in the late second 
or early third trimester could be used as an early warning tool. This report shares another similarity with our results: The investigators found no association between the difference in CL before and after cerclage and pregnancy outcome [21]. We could partly confirm these observations, at least after multivariate analysis of possible predictive parameters (Tables 2 and 3).

Significant direct correlations between the pre- and post-cerclage $\mathrm{CL}$ with pregnancy duration have already been reported previously [12]. However, it is noteworthy that in our study, only the CL after cerclage achieved independent significance for early PTD after multivariate analysis, whereas CL before cerclage did not. Nevertheless, this observation might be effect of the small sample size. However, in the multivariate analysis in women with ultrasound-indicated cerclage, it becomes evident that the adjusted odds ratios of the non-significant parameters are about one, which is in line with the high pvalues. This suggests that the lack of significance for these parameters is consistent. Accordingly, a change from the pre- to the postoperative CL would have an influence on the duration of pregnancy, but this information would be less important than the absolute CL that is achieved by the operation. Focusing on postoperative $\mathrm{CL}$ as a single factor in women who underwent ultrasound-indicated cerclage, a cut-off of $20 \mathrm{~mm}$ seems to be optimal to assess the risk for early PTD, which is quite comparable to previous results [22]. Since cerclage was indicated in cases with $\mathrm{CL}<25 \mathrm{~mm}$, we do not consider it surprising that the optimized predictive CL after surgery $(20 \mathrm{~mm})$ was similar and that this fits previous findings.

According to our model, whether the operation would result in an increase or a decrease in CL would be of only minor relevance for the final assessment of a woman's prognosis. This phenomenon is described for the first time. Taking into account that significant cervical shortening was found only in women with early PTD (Fig. 1), it is reasonable that women with a short $\mathrm{CL}$ after cerclage - the main predictive parameter - are more prone to subsequent cervical shortening. Hypothetically, this process might depend on a "peak CL" after cerclage.

Consequently, women with a short CL might benefit from the procedure only if an increase in length was achieved, and women with a long preoperative $C L$ value might not benefit from it. As reported previously, in women with a $\mathrm{CL}<25 \mathrm{~mm}$, the procedure would decrease the chance for early PTD by $30 \%$ [23]. Thus, cerclage has been emphasized to be restricted to the minority of women with a short CL [15]. Notably, $38 \%$ of women underwent history-indicated cerclage, on their own demand. This included women who received an early intervention before the 16 week despite a CL $\geq 25 \mathrm{~mm}$. Accordingly, Fig. 1 shows a median CL value in women without early preterm delivery of about $30 \mathrm{~mm}$ in week 16. It needs to be emphasized that some women with a CL $>25 \mathrm{~mm}$ might have received a cerclage later on due to shortening of the cervix. We, thus, believe that most of the beneficial outcome of cerclage in the history-indicated group was due to this assumed subset of patients.

\section{Conclusions}

$\mathrm{CL}$ measured three to six days after cerclage provides the best predictive information when compared with other perioperative parameters. After ultrasoundindicated cerclage, the optimal cut-off to assess the risk for early PTD is $20 \mathrm{~mm}$. The significant CL shortening in women with early PTD suggests that a mechanical mechanism of action contributes to the effect of cerclage. Although our study sheds new light on the issue of CL before and after cerclage, prospective, larger studies are needed to confirm our results.

\section{Abbreviations \\ CL: cervical length; IQR: interquartile ranges; PTD: preterm delivery; early \\ PTD: early preterm delivery; ROC: receiver-operating characteristics.}

\section{Competing interests}

The authors declare that they have no competing interests.

\section{Authors' contributions}

All authors substantially contributed to the manuscript: SP: the project's and the manuscript's conception and design, acquisition of data, statistical analyses, drafting the article and revising it for intellectual content, final approval of the version to be published. WE: the project's and the manuscript's conception and design, drafting the article and revising it for intellectual content, final approval of the version to be published. RP: the project's and the manuscript's conception and design, statistical analyses, drafting the article and revising it for intellectual content, final approval of the version to be published. MW: the project's and the manuscript's conception and design, statistical analyses, drafting the article and revising it for intellectual content, final approval of the version to be published. RS: statistical analyses, drafting the article and revising it for intellectual content, final approval of the version to be published. JO: the project's and the manuscript's conception and design, drafting the article and revising it for intellectual content, final approval of the version to be published. All authors read and approved the final manuscript.

\section{Acknowledgments}

There was no funding. There are no other acknowledgments to be made.

\section{Author details}

'Department of Obstetrics and Gynecology, Medical University of Vienna, Waehringer Guertel 18-20, 1090 Vienna, Austria. ${ }^{2}$ Department of Obstetrics and Gynecology, Krankenhaus Hietzing, Vienna, Austria. ${ }^{3}$ Department of Internal Medicine II, Medical University of Vienna, Vienna, Austria.

${ }^{4}$ Department of Craniomaxillofacial and Oral Surgery, Medical University of Vienna, Vienna, Austria.

Received: 8 May 2015 Accepted: 7 April 2016

Published online: 16 April 2016

\section{References}

1. Abbott D, To M, Shennan A. Cervical cerclage: a review of current evidence. Aust N Z J Obstet Gynaecol. 2012;52:220-3. 
2. O'Brien JM, Hill AL, Barton JR. Funneling to the stitch: an informative ultrasonographic finding after cervical cerclage. Ultrasound Obstet Gynecol. 2002;20:252-5

3. Hughes K, Kane SC, Araujo Júnior E, da Silva Costa F, Sheehan PM. Cervical length as a predictor of spontaneous preterm birth in high-risk singleton pregnancy - current knowledge. Ultrasound Obstet Gynecol. 2015 Oct 8. doi:10.1002/uog.15781. [Epub ahead of print].

4. Melamed N, Hiersch L, Domniz N, Maresky A, Bardin R, Yogev Y. Predictive value of cervical length in woman with threatened preterm labor. Obstet Gynecol. 2013;122:1279-87.

5. Tulandi T, Alghanaim N, Hakeem G, Tan X. Pre and post-conceptional abdominal cerclage by laparoscopy or laparatomy. J Minim Invasive Gynecol 2014 Jun 4. pii: S1553-4650(14)00301-X. doi:10.1016/j.jmig.2014.05. 015. [Epub ahead of print].

6. Berghella V, Rafael TJ, Szychowski JM, Rust OA, Owen J. Cerclage for short cervix on ultrasonography in women with singleton gestations and previous preterm birth: a meta-analysis. Obstet Gynecol. 2011;117:663-71.

7. Heath VC, Souka AP, Erasmus I, Gibb DM, Nicolaides KH. Cervical length at 23 weeks of gestation: the value of Shirodkar suture for the short cervix. Ultrasound Obstet Gynecol. 1998;12:318-22.

8. Funai EF, Paidas MJ, Rebarber A, O'Neill L, Rosen TJ, Young BK. Change in cervical length after prophylactic cerclage. Obstet Gynecol. 1999:94:117-9.

9. Hedriana HL, Lanouette JM, Haesslein HC, McLean LK. Is there value for serial ultrasonographic assessment of cervical lengths after a cerclage? Am J Obstet Gynecol. 2008;198:e701-6.

10. Roman AS, Rebarber A, Sfakianaki AK, Mulholland J, Saltzman D, Paidas MJ et al. Vaginal fetal fibronectin as a predictor of spontaneous preterm delivery in the patient with cervical cerclage. Am J Obstet Gynecol. 2003; 189:1368-73.

11. O'Connell MP, Lindow SW. Reversal of asymptomatic cervical length shortening with cervical cerclage: a preliminary study. Hum Reprod. 2001;16: $172-3$.

12. Azar ZF, Hakimi P, Ghojazadeh M, Ghatresamani F. Pre- and post-McDonald cerclage cervical length, width and funneling rate and their association with duration of pregnancy. Pak J Biol Sci. 2011:14:502-6.

13. Sim S, Da Silva CF, Araujo Júnior E, Sheehan PM. Factors associated with spontaneous preterm birth risk assessed by transvaginal ultrasound following cervical cerclage. Aust N Z J Obstet Gynaecol. 2015;55(4):344-9.

14. Pils S, Eppel W, Seemann R, Natter C, Ott J. Sequential cervical length screening in pregnancies after loop excision of the transformation zone conisation: a retrospective analysis. BJOG. 2014;121:457-62.

15. Berghella V, Mackeen AD. Cervical length screening with ultrasoundindicated cerclage compared with history-indicated cerclage for prevention of preterm birth: a meta-analysis. Obstet Gynecol. 2011;118:148-55.

16. Alfirevic Z, Stampalija T, Roberts D, Jorgensen AL. Cervical stitch (cerclage) for preventing preterm birth in singleton pregnancy. Cochrane Database Syst Rev. 2012;4:CD008991.

17. Cunningham FG, Leveno KJ, Bloom SL, Hauth JC, Rouse DJ, Spong CY, eds. Williams Obstetrics. 23 e. McGraw-Hill Medical publishing Division; 2010:218-221

18. Song JE, Lee KY, Kim MY, Jun HA. Cervical funneling after cerclage in cervical incompetence as a predictor of pregnancy outcome. J Matern Fetal Neonatal Med. 2012;25:147-50

19. Mancuso MS, Szychowski JM, Owen J, Hankins G, lams JD, Sheffield JS, et al. Vaginal Ultrasound Trial Consortium. Cervical funneling: effect on gestational length and ultrasound-indicated cerclage in high-risk women. Am J Obstet Gynecol. 2010;203:e251-5.

20. Scheib S, Visintine JF, Miroshnichenko G, Harvey C, Rychlak K, Berghella V. Is cerclage height associated with the incidence of preterm birth in women with an ultrasound-indicated cerclage? Am J Obstet Gynecol. 2009:200:e12-5.

21. Dijkstra K, Funai EF, O'Neill L, Rebarber A, Paidas MJ, Young BK. Change in cervical length after cerclage as a predictor of preterm delivery. Obstet Gynecol. 2000;96:346-50

22. Ouzounian JG, Korst LM, Lee RH. Cervical length and delivery outcomes in patients with prophylactic cervical cerclage. Am J Perinatol. 2011;28:273-6.

23. Berghella V. Universal cervical length screening for prediction and prevention of preterm birth. Obstet Gynecol Surv. 2012;67:653-8.

\section{Submit your next manuscript to BioMed Central and we will help you at every step:}

- We accept pre-submission inquiries

- Our selector tool helps you to find the most relevant journal

- We provide round the clock customer support

- Convenient online submission

- Thorough peer review

- Inclusion in PubMed and all major indexing services

- Maximum visibility for your research

Submit your manuscript at www.biomedcentral.com/submit
Biomed Central 